\title{
Gender Differences in Liver Function Tests in Coastal Karnataka
}

\author{
Usha Sachidananda Adiga \\ Associate Professor, Department of Biochemistry Karwar Institute of Medical Sciences, Karwar, Karnataka
}

\begin{abstract}
:
Background: Studies have indicated the role of gonadal hormones in regulating structure and function of nearly every tissue and organ in the mammalian body,causing gender differences in a variety of characteristics. Objective of our study is to compare the gender differences in liver function tests in healthy individuals and to find the correlation between bilirubin and other liver markers.

Methodology: The retrospective study was conducted by collecting the data from the Clinical Biochemistry Laboratory. Liver function tests were compared among 35 women and 35 men, who got their liver function tests done as a part of routine investigation panel.Comparison of liver parameters were done using independent Student's ' $T$ ' test. Correaltion study was done by calculating Pearson's correlation coefficient.

Results: Total and direct bilirubin were very significantly high in males as compared to females ( $P=0.002$ and $P=0.001)$. We found a significantly high AST $(P=0.039)$ and albumin $(P=0.034)$ in males.AST was positively very highly significantly $(P<0.0001)$ correlated with total and direct bilirubin $(r=0.56$ and $r=0.7149$ respectively).
\end{abstract}

Conclusion:We observed a significantly low total and direct bilirubin, AST and albumin levels in women compared to men. The causative factor is inconclusive and association of liver profile and female gonadal hormones needs further research.

Key words: Bilirubin, AST, albumin, gender difference

Running title:Liver profile and gender difference

\section{Introduction}

Gonadal hormones have a role in the development of gender specific traits and affect primarily structure and function of gender specific organs.Studies have indicated their role in regulating structure and function of nearly every tissue and organ in the mammalian body,causing gender differences in a variety of characteristics.

Sex hormones are associated with various aspects of reproduction, differentiation, development, growth and homeostasis,influence the development of female and male specific traits.A number of studies indicate its role in regulating structure and function of nearly all tissues and organs including brain,bones,liver,kidneys causing differences in males and females (1).

Protective role of estrogen has been well established in health and disease and it is responsible for the gender differences in various biochemical markers. There are a few studies available comparing liver parameters in both the genders $(2,3)$.There is a limited availability of literature that provides information on this area to the best of our knowledge.

Objective of our study is to compare the gender differences in liver function tests in healthy individuals.We also aimed to find the correlation between bilirubin metabolism and other liver functions.

\section{Methodology}

The retrospective study was conducted by collecting the data from the Clinical Biochemistry Laboratory attached to a government medical college in coastal Karnataka. Liver function tests were compared among 35 women and 35 men. Their mean age was $52.71 \pm 2.05$ years and $48.74 \pm 1.48$ years respectively. Inclusion criteria: healthy individuals who got their investigations done as a part of routine check up. Exclusion criteria: Liver disorders, diabetes mellitus, alcoholics, those with any known systemic illnesses.

Total bilirubin, direct bilirubin, aspartate transaminase (AST), alanine transaminase (ALT),alkaline phosphatase (ALP), total protein and albumin were estimated in liver function panel using commercially available kits with Transasia XL-640,automated chemistry analyzer.Comparison of liver profile was done between females and males.

Statistical analysis was done by applying Student's independent ' $t$ ' test using SPSS software. Correlation study was done by calculating Pearson's correlation coefficient, $r$ (between -1 and +1 ).Level of significance was fixed at $P<0.05$. 


\section{Results}

Total and direct bilirubin were very significantly high in males as compared to females ( $P=0.002$ and $P=0.001)$. We found a significantly high AST $(P=0.039)$ and albumin $(P=0.034)$ in males. There was no significant gender difference in ALT levels, AST/ALT ratio, ALP and total proteins as given in Table 1.AST was positively very highly significantly $(\mathrm{P}<0.0001)$ correlated with total and direct bilirubin $(\mathrm{r}=0.56$ and $\mathrm{r}=0.7149)$.

Table 1: Showing gender differences in liver function tests in normal individuals

\begin{tabular}{|c|c|c|c|}
\hline $\begin{array}{c}\text { Liver parameter } \\
\begin{array}{c}\text { Total bilirubin } \\
(\mathrm{mg} / \mathrm{dl})\end{array}\end{array}$ & Females & Males & P value \\
\hline $\begin{array}{c}\text { Direct bilirubin } \\
(\mathrm{mg} / \mathrm{dl})\end{array}$ & $0.50 \pm 0.05$ & $0.86 \pm 0.09$ & $0.002^{* *}$ \\
\hline $\begin{array}{c}\mathrm{AST} \\
(\mathrm{U} / \mathrm{L})\end{array}$ & $23.29 \pm 1.37$ & $33.45 \pm 4.58$ & $0.039^{*}$ \\
\hline $\begin{array}{c}\text { ALT } \\
(\mathrm{U} / \mathrm{L})\end{array}$ & $20.97 \pm 2.34$ & $23.84 \pm 2.26$ & 0.38 \\
\hline $\begin{array}{c}\text { AST/ALT } \\
\text { ALP }\end{array}$ & $1.48 \pm 0.17$ & $1.66 \pm 0.21$ & 0.5 \\
\hline $\begin{array}{c}\text { AL/L) } \\
\text { Albumin } \\
\text { (g/dl) }\end{array}$ & $88.37 \pm 6.06$ & $80.97 \pm 5.11$ & 0.354 \\
\hline $\begin{array}{c}\text { Total Proteins } \\
(\mathrm{g} / \mathrm{dl})\end{array}$ & $6.7 \pm 0.95$ & $4.15 \pm 0.1$ & $0.034^{*}$ \\
\hline
\end{tabular}

$* \mathrm{P}<0.05$ - significant

$* * \mathrm{P}<0.01$ - highly significant

\section{Discussion}

We found a significant gender difference in bilirubin (total and direct),AST and albumin. There was no significant gender difference in other liver parameters. Our study is supported by Rosenthal and colleagues, who reported a declined bilirubin levels in females (2). This could be attributed to increased rate of conjugation and excretion of bilirubin in females due to the influence of gonadal hormones. However the above study contradicts our correlation between bilirubin and AST. It states that bilirubin metabolism is independent of other functions of liver, which are not concerned with bile pigment processing. However we cannot justify this fact as our sample size is small.

Our study is in accordance with that by Mera et al which also suggest a low AST levels in women (3). But contrary to our study, they also found decreased ALT and high AST/ALT ratio in women. We have noted a insignificantly low AST/ALT ratio in the present study. Discrepancies were noted in ALT in different genders with same living conditions(4-7).Comparatively high ALT was reported in females (8-10). This variation in liver enzymes is attributed to the hormonal status and difference in the muscle mass (9).However role of female gonadal hormone in altering biochemistry of liver could be inconclusive. Moore et al and Darj et al studied the effect of estradiol supplementation on liver markers $(11,12)$.They found no elevations in liver enzymes and bilirubin levels after hormone replacement therapy.Crippin and colleagues compared liver profile in postmenopausal women with and without estrogen containing hormone replacement therapy (13).They reported that there was no elevation in bilirubin levels in women on hormone replacement therapy. Contradictory reports were given by Guattery and colleagues who stated heightened bilirubin levels in biliary cirrhotic women treated with hormones, necessitating cessation of therapy (14).

Our findings on plasma proteins are supported by the report by Devi and colleagues (15).Low albumin levels in women could be due to increased degradation. This study states that the rate of protein synthesis is lower in females compared to males (15).

Limitation of the study: Small sample size is the limitation of our study. 


\section{Conclusion}

We observed a significantly low total and direct bilirubin, AST and albumin levels in women compared to men. A significant correlation between bilirubin and AST was found.The causative factor for gender difference is inconclusive and association of liver profile and female gonadal hormones needs further research.

\section{Acknowledgements}

Sincere thanks to Dr Poornima RT,Head of the Department Biochemistry for the support. Conflicts of interest: None

Funding: Nil

\section{References}

[1]. Ivan S,AbdulRA,WolfgangEB,ChristophW,Andrew B,Gerhard B.Gender differences in kidney function.Eur J of Physiol 2007;455:397-429.

[2]. Philip Rosenthal,MatthewPincus,DanielFink.Sex- and Age-Related Differences in Bilirubin Concentrations in Serum.Clin chem1984; 30(8): 1380-1382.

[3]. MeraJR,DicksonB,FeldmanM.Influence of gender on the ratio of AST and ALT in patients without hyperbilirubinemias.Dig Dis Sci 2008;53(3):799-802

[4]. Clark JM, Brancati FL, Diehl AM: The prevalence and etiology of elevated aminotransferase levels in the United States. The American journal of gastroenterology 2003; 98(5):960-967.

[5]. Cotler S, Dhamija M, Luc B, Siqueira F, Bartram A, Layden T, Wong S: Theprevalence and clinical correlates of elevated ALT levels in an urban Chinatowncommunity. Journal of Viral Hepatitis 2010;17(2):148-152.

[6]. Pendino GM, Mariano A, Surace P, Caserta CA, Fiorillo MT, Amante A, Bruno S,

[7]. Mangano C, Polito I, Amato F. Prevalence and etiology of altered liver tests: Apopulation-based survey in a Mediterranean town. Hepatology 2005; 41(5):1151-1159.

[8]. Chen CH, Huang MH, Yang JC, Nien CK, Yang CC, Yeh YH, Yueh SK: Prevalence

[9]. and etiology of elevated serum alanine aaaminotransferase level in an adult population in Taiwan. Journal of gastroenterology and hepatology 2007;22(9):1482-1489.

[10]. Mijovic V, Contreras M, Barbara J: Serum alanine aminotransferase (ALT) and gamma-glutamyltransferase (gamma-GT) activities in north London blood donors.Journal of clinical pathology 1987;40(11):1340-1344.

[11]. Poustchi H, George J, Esmaili S, Esna-Ashari F, Ardalan G, et al. Gender Differences in Healthy Ranges for Serum Alanine Aminotransferase Levels in Adolescence. PLoS ONE 2011;6(6): e21178.

[12]. Chen SC-C, Yeh J-J, Chang M-H, Liao Y-K, Hsiao L-C, et al.Gender Difference of Alanine Aminotransferase Elevation May Be Associated with Higher Hemoglobin Levels among Male Adolescents. PLoS ONE 2010;5(10): e13269.

[13]. Moore B, Paterson M, Sturdee D. Effect of oral hormone replacementtherapy on liver function tests. Maturitas 1987; 9: 7-1 5.

[14]. DarjE, Axelsson 0, Carlstrom K, Nilsson S, von Schoultz B. Liver metabolism during treatment with estradiol and natural progesterone.GynecolEndocrinol 1993; 7: 111-1 14.

[15]. Crippin JS, Jorgensen RA, Dickson ER, Lindor KD. Hepatic osteodystrophyin primruy biliary cirrhosis: effects of medical treatment. AmJ Gastroenter 1994; 89: 47-50.

[16]. Guattery JM, Faloon WW. Effect of estradiol upon serum enzymes inprimary biliary cinhosis. Hepatology 1987; 7: 737-742.

[17]. RenukaDevi ,Mallem Pravin Kumar, Effect of Ageing and Sex on the Caeruloplasmin (Cp) and the Plasma Protein Levels. Journal of Clinical and Diagnostic Research. 2012 ; 6(4): 577-580. 